\section{Crack Path Prediction Under Fretting Fatigue $-A$ Theoretical and Experimental Approach}

In this paper, the direction of crack growth under fretting fatigue loading is studied through an experimental and theoretical approach. The experimental work enabled the fretting conditions to be known and the site of initiation and crack trajectory to be viewed; theoretical work permitted a prediction of those processes. Fretting wear and fretting fatigue loadings induce non-proportional mixed mode loading at the tip of the cracks initiated within the contact zone. The classical criteria predicting the direction of crack growth cannot account for the non-proportional loading. Tests were carried out to study the cracking phenomena under cumulative effects of contact and external loadings, i.e., fretting fatigue loading. The fretting contact between the two contacting bodies is modeled to evaluate the operating contact loading conditions. The response of the cracked body is determined in terms of stress intensity factors using the continuous distribution of dislocations theory coupled with a unilateral contact analysis with friction. The angle of crack extension is then predicted, at different stages of crack life, according to a new approach. The correlation of the predicted angle of crack extension with the experimental observation enables the conclusion that, under fretting fatigue loading, cracks propagate by a mode I process.
V. Lamacq

M. C. Dubourg

Laboratoire de Mécanique des Contacts CNRS URA 856,

Institut National des Sciences

Appliquées de Lyon,

20 avenue Albert Einstein

69621 Villeurbanne Cedex, France

L. Vincent

Département Matériaux-Mécanique

Physique, CNRS URA 447,

Ecole Centrale de Lyon,

36 avenue Guy de Collongue,

BP 163, 69131 Ecully Cedex, France

\section{Introduction}

Fretting loading still remains a significant concern in designing and maintaining industrial structures (Waterhouse, 1972, 1981 ). It is sometimes responsible for premature fatigue failure and often limits component life (Forsyth, 1981; Hoeppner, 1974). It occurs in quasi-static assemblies such as splines, cables, turbine blade assemblies etc. Fretting damage is divided into fretting wear and fretting fatigue (Waterhouse, 1972, 1981). The development of long cracks is not restricted to fretting fatigue but occurs also in fretting wear, as demonstrated by Vingsbo and Soderberg (1988), Vincent et al. (1992), and Zhou (1992). Cracks initiate at a very early stage and most of the components life incorporates crack growth. They are submitted to mixed mode non-proportional loading, and complex contact conditions exist at their interface, including frictional locking.

A general approach is required to predict crack behavior under fretting loading. The combination of high stress concentration in the contact zone area, multiaxial stress field and nonproportional conditions, tensile and compressive regions varying in location and intensity during load cycles, makes conventional design methods unsuitable.

In fatigue crack problems, semianalytical methods offer an interesting alternative compared to numerical methods. Hence, stress intensity factors (SIFs) in mode I and II are calculated for parallel (Comninou, 1977; Keer et al., 1980; Sheppard et al., 1987), perpendicular (Hills and Comninou, 1985; Sheppard et al., 1986) and slanted cracks (Keer and Bryant, 1983; Bower, 1988), under various loading conditions considering frictional locking. The formulation rests on the modeling of discontinuities of displacement through a continuous distribution of dislocations (Dundurs and Mura, 1964). In most of these formulations, a priori assumptions concerning the contact conditions along each crack face are required. Dubourg et al. (1988) developed a method that determines the contact zone division along the crack faces avoiding any previous hypothesis. It is based on a modified dislocation theory and on the unilateral frictional contact analysis. The model is applied to the study of perpendicular cracks (Dubourg et al., 1988), slanted cracks (Dubourg and Villechaise, 1989), bent cracks (Dubourg and Villechaise, 1992 ) and multiple straight cracks (Dubourg et al., 1992a, b). More recently, the propagation of a fatigue crack network under Mode I was studied. (Dubourg and Lamacq, 1994).

This model is extended to include crack propagation to estimate component life under fretting fatigue loading. This requires the knowledge of crack path and crack growth laws. Criteria for the determination of angles of crack growth under proportional mixed mode conditions are now well established (Erdogan, 1963; Sih, 1974; Tirosh, 1977), but only a few theoretical studies are devoted to non-proportional conditions. Bold et al. (1992), Smith and Pascoe (1983) showed the inapplicability of existing criteria. Bower (1988) succeeded in predicting the angle of crack extension of a lubricated crack under rolling conditions. Crack growth laws, generally expressed in terms of SIF variation (the best known is the Paris law, 1964), are directly obtained from experimental data.

Fretting fatigue conditions involve non-proportional loading at crack tips. The aim of this work is to predict the direction of crack growth during the propagation process. A combined theoretical and experimental approach is used to achieve this target. Fretting fatigue tests are carried out to study cracking phenomena and in particular the site of crack nucleation and the crack path progression. The operating conditions and the cracks involved in the contact area are modeled according to a fatigue crack model. This double approach proposes a method to predict the angle of crack growth.

\section{Theoretical Approach}

II.1 The Fretting Fatigue Crack Model. The fretting fatigue crack model is composed of:

The fretting contact model. It determines the contact area, the normal and tangential tractions, the stick and slip regions between two bodies submitted to contact loading (constant normal force and oscillatory tangential force) and constant external 
traction. The contact problem between the two-dimensional elastic bodies is solved as a unilateral contact problem with friction. Coulomb's law is used for lack of anything better. An incremental description of the tangential loading is employed to account for the hysteresis induced in the contact. As semiinfinite bodies are considered, Boussinesq and Cerruti potentials are used. Relations between displacements and stresses are obtained. The potential area of contact is discretized into segments on which tractions are assumed constant. Comparisons with the literature (Johnson, 1985) were performed.

The fatigue crack model. It determines the cracked body response. The continuous distribution of dislocations theory to describe crack behavior coupled to the unilateral contact analysis between the crack faces leads to the determination of the stress field of the cracked body and the SIFs at crack tips. This fatigue crack model of Dubourg is fully described in previous papers, as mentioned in the introduction (Dubourg, et al., 1988; Dubourg and Villechaise, 1989)

Criteria for the determination of the angle of crack extension. A review of existing criteria under proportional loading and studies on non-proportional loading is presented in the next paragraph.

II.2 Proportional and Non-Proportional Conditions. The fretting fatigue conditions induce non-proportional mixedmode loading at the tip of cracks. Non-proportional loading is characterized by a varying ratio $K I / K I I$ during a load cycle while proportional loading is characterized by a constant ratio.

Proportional Conditions. As a starting point, a literature survey concerning the determination of direction of crack growth under mixed-mode loading (Vincent et al., 1994) was carried out. Three criteria were selected among the various classical ones to be applied to non-proportional loading, as no restrictive assumption either on the angle of crack extension, or the load conditions is formulated. These are the MTS-criterion (Maximum Tangential Stress) of Erdogan and Sih (1963), the criterion of Tirosh (1977) (maximum of $\left(\sigma_{\theta \theta}^{2}-\sigma_{r r}^{2}\right)$ ) and finally the S-theory of Sih (1974) (minimum of strain-energydensity). The angle of crack extension is determined by the extreme value of the specific parameter of the criterion. As pointed out by Short and Hoeppner (1989), these three criteria give roughly the same results.

These three criteria are implemented in Dubourg's fatigue crack model. The determination of the angle of crack extension for simple crack geometries (perpendicular or inclined, straight crack in an semi-infinite plate and infinite plane) and various loading conditions (uniaxial, biaxial proportional loading) is performed. Good agreement with the literature's results is obtained.

The most common formulation of these criteria is expressed in terms of $K I, K I I$, and $\theta$. It is straightforward as long as cracks are straight. The reference line to calculate the angle of extension is identical to the initial crack direction. Under contact loading, cracks may have complex geometries. When the crack is bent or has already branched, the definition of the reference line and therefore the analytical expression of the SIFs is not clear. To avoid any assumption on the reference line direction of a bent crack, the crack path determination is performed here through the stress field of the cracked body. The components of the stress field are calculated on a boundary encircling the crack tip. This boundary is a circle of imposed radius ( Sih, 1991 ) or it corresponds to the elasto-plastic boundary at the crack tip (Theocaris and Andrianopoulos, 1982) calculated with the Von Mises criterion. As presented in the next section, the applicability of these three criteria to non-proportional loading is not immediate.

Application to Non-proportional Conditions. Some studies (Bold et al., 1992; Smith and Pascoe, 1983) on non-proportional loading showed the inapplicability of certain classical criteria to describe crack propagation under out of phase loading histories. For instance, Truchon and Amestoy (1981) were faced with a mathematical incompatibility when writing the conditions of propagation of their criterion over a whole non-proportional loading cycle. Hourlier et al. (1982) applied the $k l_{\max }^{*}$ and $\Delta k 1_{\max }^{*}$ criteria under non-proportional conditions. These criteria could not account for their experimental results. But they observed that, depending on the material, the direction of crack growth is governed by both $k_{1 \max }^{*}$ and $\Delta k_{1 \max }^{*}$ Hence, two variables influence crack propagation ( $K$ and $\Delta K$ or, for ex ample, $K_{\sigma}$ and $\Delta K_{\sigma}$ ) and therefore the crack path direction. The difficulty lies in the fact that the evolution of a quantity (for instance $k 1^{*}$ ) as a function of $\theta$ during a loading cycle is different from the variation of the amplitude of this quantity $\left(\Delta k 1^{*}\right)$ depending on the angle of calculation.

Proportional and non-proportional loading conditions must actually be distinguished as proved by Socie (1987). He performed tests where both proportional and non-proportional loading histories were considered. Out of phase loadings appeared to be more damaging than proportional ones, further cracks extended in different directions depending on the loading and the phase of the non-proportional condition.

Another difficulty is introduced by the non-proportional loading. The crack angle predicted during a whole non-proportional loading cycle is different at each step of the cycle, whereas the expected crack angle remains the same throughout a complete proportional loading cycle. Hence, Bower (1988) noticed that there is no unique value of $K_{\sigma}^{\max }$ and $\theta_{0}$. So, he suggested that the crack would tend to propagate in the direction of the maximum value of $K_{\sigma}^{\max }$. But he could not justify this assumption due to lack of experimental investigation. As a second approach, he assumed that the crack would grow when subjected to higher values of $\Delta K_{\sigma}^{\max }$. The predictions of his model were thus consistent with the features of pitting cracks observed in practice. Actually, this approach pointed out the need for a complementary parameter to select one angle corresponding to the experimental growing crack angle.

Complementary Parameters for Non-Proportional Loading. As the classical criteria mentioned above cannot account for non-proportional loading, the ability of complementary parameters to describe this problem was studied. Bold (1992) tried to analyze the evolutions of $K_{\sigma}^{\max }$ and of $K_{\tau}^{\max }$, the factor governing the MSS-criterion, Keer and Bryant (1983) proposed a parame-

\footnotetext{
Nomenclature

$$
\begin{aligned}
\sigma_{i}, i=1,2= & \text { principal stress } \\
\theta_{0}= & \text { angle of crack extension } \\
& \left({ }^{\circ}\right) \\
Q(t)= & \text { tangential force } \\
Q^{*}= & \text { maximum value of } Q . \\
& \text { positive from left to right; } \\
& \text { negative from right to left } \\
F n= & \text { normal force }
\end{aligned}
$$

$$
\begin{aligned}
f= & \text { coefficient of friction } \\
\sigma_{D}= & \text { strength stress } \\
\delta= & \text { imposed displacement on the sur- } \\
& \text { face } \\
a= & \text { half width of the loading zone } \\
c= & \text { half width of the sticking zone of } \\
& \text { the contact }
\end{aligned}
$$

$$
\begin{aligned}
b= & \text { half length of the crack } \\
\beta= & \text { inclination of crack } \\
& \text { from the surface } \\
K I(i), K I I(i)= & \text { open mode and sliding } \\
& \text { mode stress intensity } \\
& \text { factors of crack } i \\
k 1^{*}= & \text { stress intensity factor on }
\end{aligned}
$$
a branched crack
} 


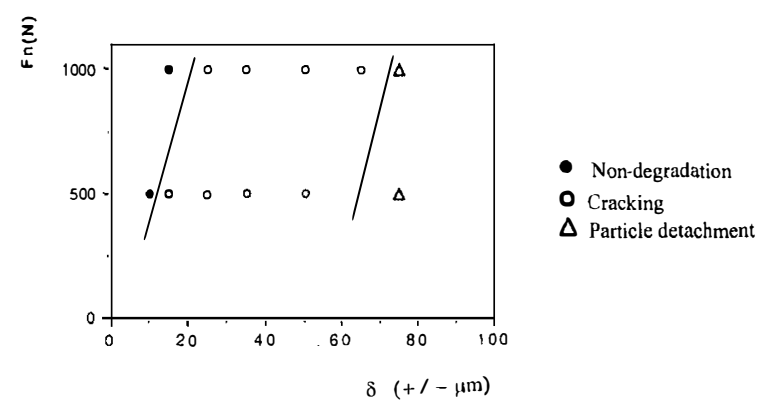

Map 1 Material response fretting map of 7075 aluminium alloy. (Vincent et al., 1994)

ter $\overline{K I}=C_{1} K I+C_{2} K I I$ under proportional loading. $C_{1}$ and $C_{2}$ are $\theta_{0}$ related. This last formulation appears practical. Actually, the two varying parameters $(K I$ and $K I I)$ are combined to lead to a single parameter approach. Even though Keer and Bryant defined it under proportional loading it may be of interest to test it under a non-proportional loading. It makes the crack angle determination easier.

Experimental data or theoretical results on crack behavior under non-proportional loading are rare and refer to rolling, sliding or fretting contacts where pitting or squats are generally initiated (Kaneta et al., 1985; Keer and Bryant, 1983; Sin and Suh, 1984; Xiaogang et al., 1988). Only embryonic answers are proposed, but without a general law for crack path and crack growth determination.

In conclusion, no general law or criterion can be directly applied to predict the angle of crack extension under non-proportional loading.

\section{Application to Fretting-Fatigue Experiment}

A lot of work has been done in tribology during the last ten years. Fretting simulators were specially designed and a new methodology centered on the third body concept, the Velocity Accommodation Modes (VAMs) (Godet, 1984); (Berthier et al., 1986); (Vincent et al., 1992a,b) and on the fretting maps initially originated by Vingsbo and coworkers (Vingsbo and Soderberg, 1988); (Vingsbo et al., 1989) was developed by Godet and his coworkers at the Laboratoire de "Mécanique des Contacts" and at the Laboratoire" Matériaux-MécaniquePhysique," in Lyon (France). Fretting maps serve today to determine the actual fretting regime and to identify contact cinematic conditions (adhesion, partial slip, gross slip) (Vingsbo and Soderberg, 1988); (Vingsbo et al., 1989). Here, two fretting maps are used. The Running Conditions Fretting Map (RCFM) plots normal load $F n$ versus nominal displacement amplitude for a given frequency and a given roughness (See Map 2). The difference with the Vingsbo approach is that the map has been drawn for different numbers of cycles which shows that the three cinematic conditions vary in extent during the test (Vincent et al., 1992b). The Material Response Fretting

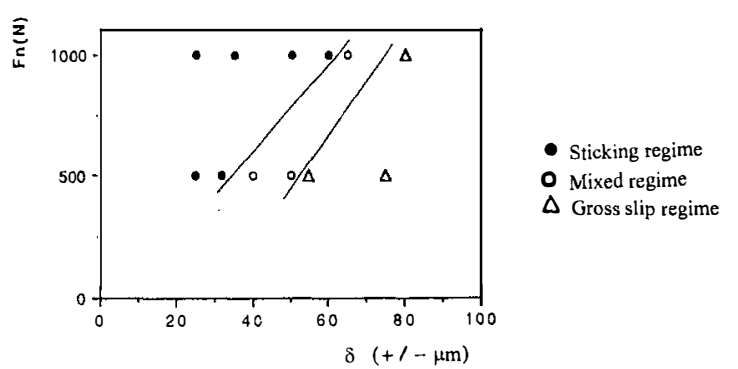

Map 2 Running conditions fretting map of $\mathbf{7 0 7 5}$ aluminium alloy after $5.10^{4}$ cycles (Vincent et al., 1994)
Table 1 Mechanical properties

\begin{tabular}{lrr}
\hline Aluminium alloy & 7075 & 2024 \\
Young's modulus (MPa) & 72000 & 72500 \\
Poisson's ratio & 0.3 & 0.3 \\
$\sigma D(\mathrm{MPa})$ & 230 & 180 \\
\hline
\end{tabular}

Map (MRFM) plots stress or equivalent stress versus displacement amplitude (See Map 1). Three zones corresponding to three material responses are identified: no superficial degradation, cracks and plastic deformation and finally particle detachment zones. Partial slip clearly appears as the most detrimental mode for crack initiation. Critical values of slip amplitude were found for which fretting fatigue crack propagation is high (Pellerin, 1990).

The running conditions for the fretting fatigue tests presented here are determined according to information obtained from the RCFM and the MRFM available for the aluminium alloys and the ball on flat geometry considered in this study. Running conditions corresponding to partial slip regime and leading to crack initiation and propagation are imposed (see Maps 1,2). The modeling of the fretting fatigue experiments requires data such as the friction coefficient, the tangential force variation, the normal force and also the location, profile and evolution of the cracks. These data are obtained from experimental observations. Then, the angle of crack growth at different stage of propagation is predicted according to the classical criteria completed by a complementary factor.

III.1 Material. Two aluminium alloys were tested (7075, 2024). Their mechanical properties are reported in Table 1. For these two alloys, the thermomechanical treatments respect the aeronautical specifications.

III.2 Test Procedure. The notations used in this paragraph are reported in Fig. 1. The fretting fatigue apparatus is based on the fretting wear device developed at the Ecole Centrale de Lyon (Zhou and Vincent, 1993). This fretting wear device was superimposed on a static loading frame. The full description of the fretting-fatigue apparatus is reported elsewhere (Reybet-Degat and Vincent, 1994). The dimensions of the sample and a brief description of the apparatus are reported in Fig. 2.

A spherical aluminium alloy piece (labeled (2) in Fig. 2(a)) is pressed against the planar tested sample (labeled (1) in Fig. $2(a))$ of the same alloy. This normal force, $F n$, remains constant during the entire test. The spherical body is submitted to an oscillating micro-displacement, $\delta$, through a piston ring (labeled (3) in Fig. 2(a)) and thus rubs against the planar specimen. This micro-displacement prompting on the surface induces an oscillating tangential force, $Q(t)$, in the contact area. The planar piece also undergoes a static uniaxial traction equal to

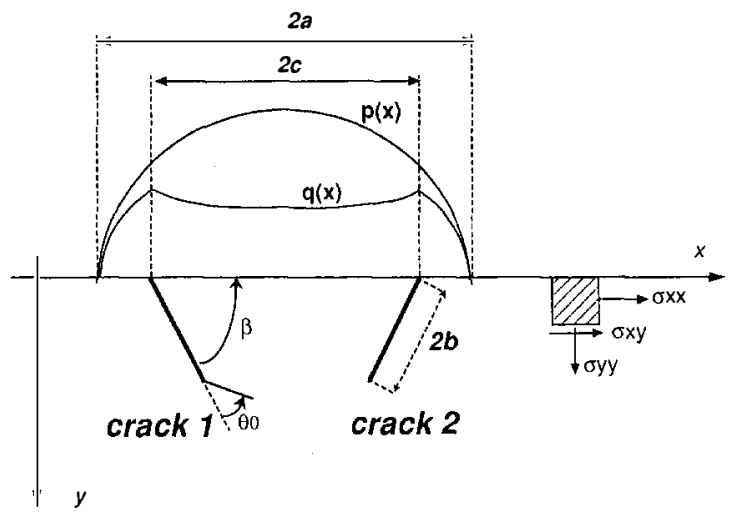

Fig. 1 Notations used for the contact problem and the crack description 


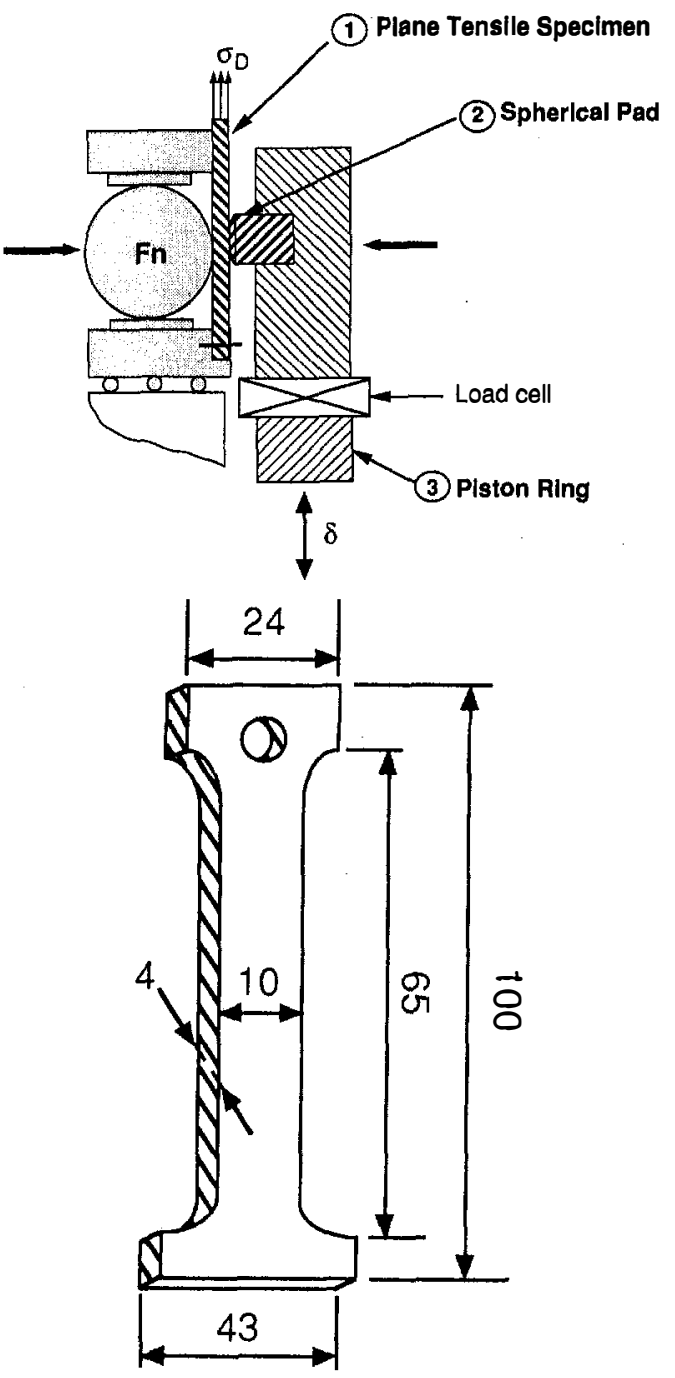

Fig. 2 Fretting fatigue apparatus and plane tensile specimen dimensions (in millimeters)

the fatigue limit, $\sigma_{D}$, of the aluminium alloy Note that the value of $\sigma_{D}$ was experimentally obtained, dynamically, for an $R$ ratio ( $R=\sigma_{\min } / \sigma_{\max }$ ) equals 0.1 . The planar sample is submitted to this specific value for two main reasons. First of all, $\sigma_{D}$ is a well known, meaningful characteristic of materials. Secondly, it appeared of interest to analyze the degradations induced by a constant traction of value $\sigma_{D}$, under which no failure should appear, associated with a contact loading. Tangential and normal forces and also the micro-displacement acting in the contact area are recorded throughout the test, resulting in a friction-log curve at the end of each of them (Fig. 3). The experimental conditions for the experiment on 7075 aluminium alloy are reported in Table 2 .

III.3 Experimental Observations. First, it is of interest to note that the experiments are reproducible. The same test conditions were representative of the same fretting regime and material response (location, length and inclination of the cracks). The recording of the progression of the crack during a run test is not possible. The crack evolution (length, inclination) versus the number of cycles is obtained from information collected from several tests conducted for different number of cycles. At the end of each test, crack dimensions are measured destructively. The 7075 and 2024 aluminium alloys behave similarly in terms of crack initiation and propagation angles under the fretting regime considered here. Therefore, here, results concern the 7075 aluminium alloy.

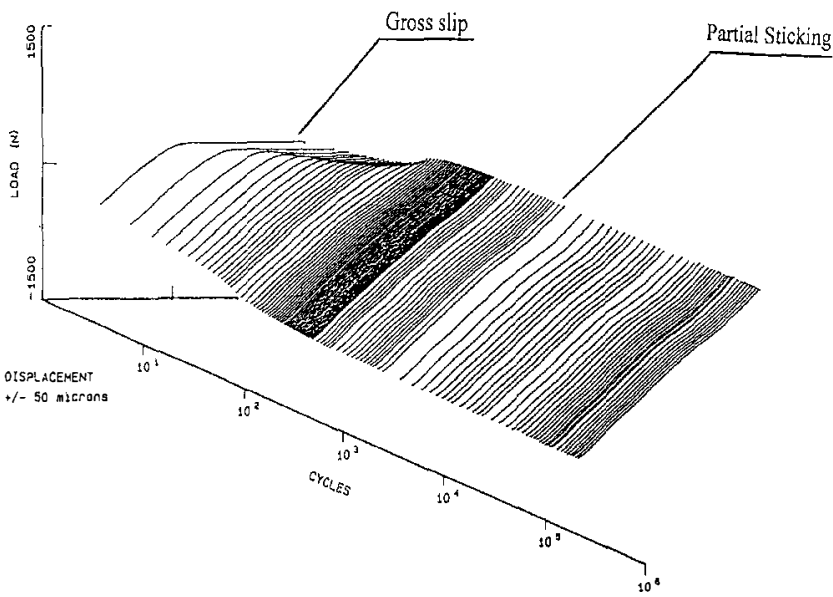

Fig. 3 Friction log for a 7075 alloy test. $F n=100$ daN; $\delta=+/-35 \mu \mathrm{m}$ frequency $=5 \mathrm{~Hz} ; \sigma_{D}=230 \mathrm{MPa}$; number of cycles $=3.10^{5}$.

The Fretting Contact Conditions. Modeling of the fretting test requires data such as the friction coefficient, the tangential force amplitude, the normal force and also the crack location, profile and evolution. Both evolutions of tangential force, $Q(t)$, and imposed displacement, $\delta$, are given by the friction-log curve (Fig. 3) whose loops also identify the regime acting in the contact at each load cycle. Normal force, Fn, is constantly recorded. After a number of runs, it remains constant. The direct observation of the relief and of the different surfaces of the contact zone enables the estimation of the size of the sticking $(2 c)$ and the sliding $(2 a-2 c)$ zones (Fig. 4). The coefficient of friction, $f$, cannot be attained directly from the examination of the experimental data. It is therefore estimated by comparing experimental variables $(2 a, 2 c)$ with the theoretical values obtained according to the fretting contact model described in Section II.1.

The Fretting Regime. The friction-log curve for 7075 aluminium alloy after a $3.10^{5}$ cycles is presented in Fig. 3. A mixed regime next to the sticking regime is observed. At the beginning of the experiment, the fretting loops are open. Grossslip and dissipation of energy take place in the contact. After about 100 runs, these loops remain closed. In fact, during the first 100 runs, the contact morphology changes to lead to its stable regime which is partial stick. All the "undesirable" particles were ejected from the contact to achieve an equilibrium. The fretting loops remain closed and no gross slip regime occurs, until the end of the test.

Stick and Sliding Zones. Two distinct domains appear from the direct observation of the contact zone surface (Fig. 4(a)). The central zone of the contact is a disk encircled by an annulus whose boundary is blurred. The central disk corresponds to a stick zone of size $2 \mathrm{c}$ and the outer annulus of size $(2 a-2 c)$ corresponds to a micro-sliding zone (Fig. 4(b)). A cross-section of the specimen is shown in Fig. 5( $a)$. The relief of these two domains clearly shows that the outer area is more damaged than the inner central one (Fig. 5(b)). Studies on surface damage and tribological surface transformation (Zhou, 1992)

\section{Table 2 Experimental conditions}

Amplitude of imposed displacement $\delta: \pm 35 \mu \mathrm{m}$

Frequency: $5 \mathrm{~Hz}$

Normal force Fn: 1000N

Static uniaxial traction: $\sigma D$.

Number of cycles: $5.10^{4}$ to $10^{6}$

Radius of spherical sample: $0.3 \mathrm{~m}$ 


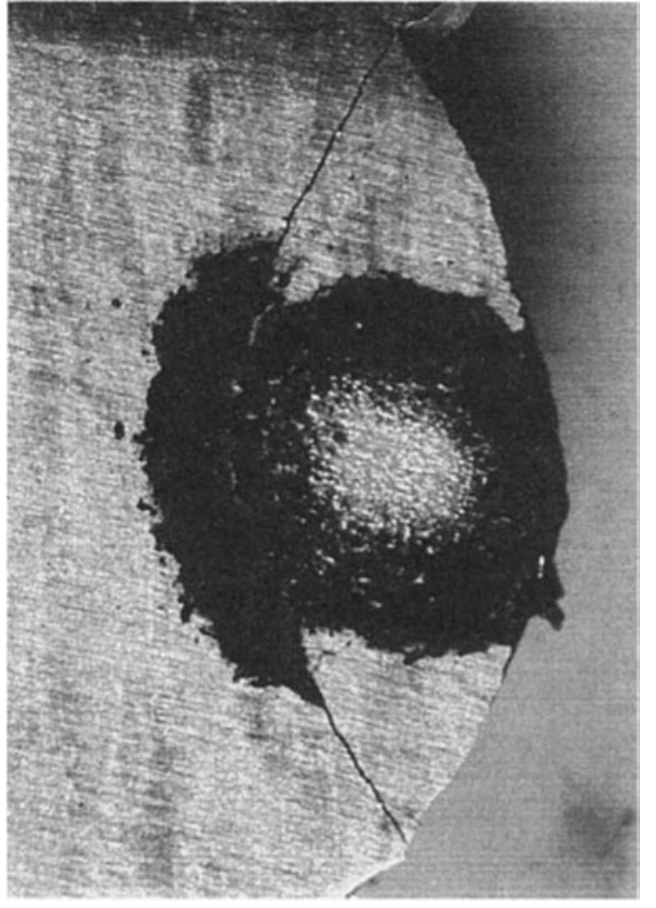

Fig. 4(a) View of the surface contact. "eye-shape" of the cracks $2 a$

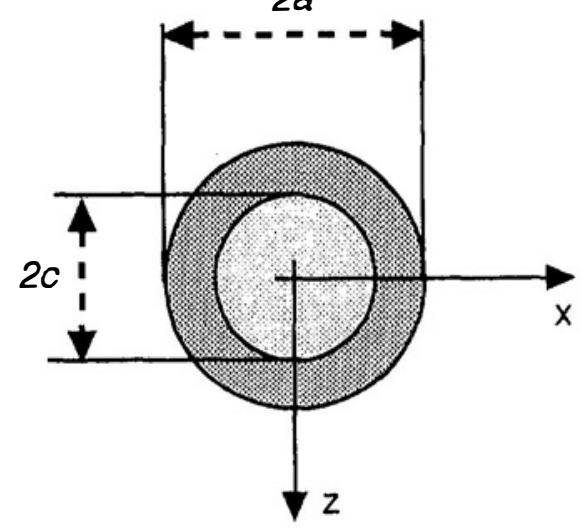

Fig. $\mathbf{4 ( b )}$ Schematic view of the contact

showed that the slip condition and, equivalently, the microsliding condition is more damaging for the surface than the stick condition. In fact, more wear damage is involved during sliding. The particle loss is facilitated by the sliding displacement, unlike in a stick zone where particles are locked. There is no significant observable plastic deformation at the surface of the specimen at the end of the test. The depth of deterioration in the sliding zone due to spall detachment is less than $10 \mu \mathrm{m}$.

Coefficient of Friction. The friction coefficient, $f$, is assumed to be constant within the contact area and independant of time. It is also supposed that micro slipping only occurs when the tangential stress is higher than the product of $f$ and the normal stress. This introduces a slip threshold and defines slip and adhesion areas in the same contact (Godet, 1988). The value of $f$ during the test is determined according to these two assumptions. As no gross slip occurs during the test, this coefficient is greater than $930 / 900\left(Q^{*} / F n\right)$. (See experimental values in Table 3.) $\mathrm{f}$ is imposed so that the slip and adhesion areas determined by the fretting contact model correspond to the experimental areas. Experimental values of $F n$ and $Q(t)$ are used as data for the fretting contact solution. The friction coefficient imposed was 1.2.

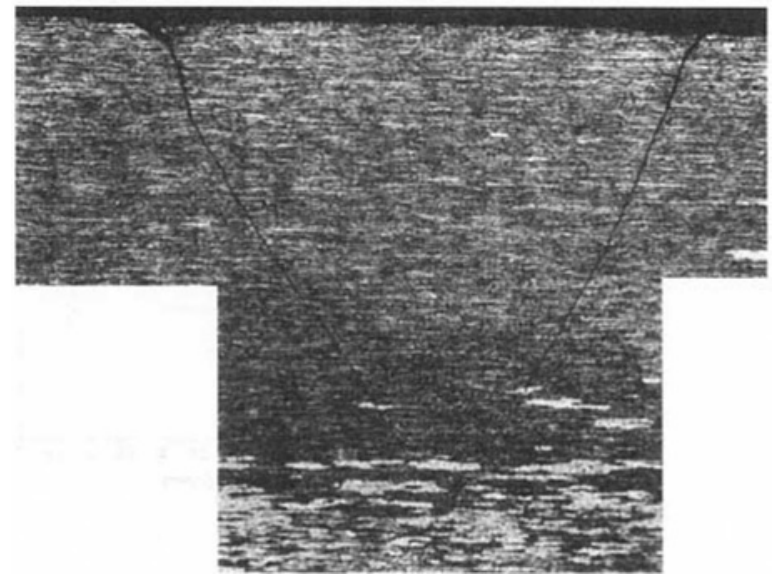

Fig. 5(a) Cross-sectional view of a 7075 cracked sample

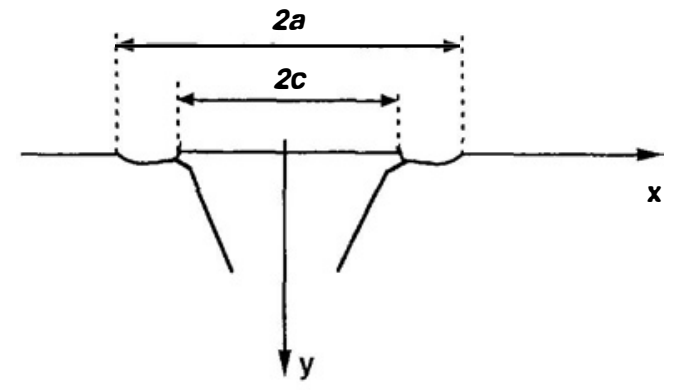

Fig. 5(b) Schematic relief of the contact area

Crack Morphology. Many cracks initiate under the contact zone, but only two of them, situated symmetrically from the center of the contact, propagate whilst all the others are self arrested.

On plane specimen surface $(x 0 z)$, the two cracks propagate perpendicularly to the fretting direction, with a semi-elliptical shape. They join each other at each edge of the specimen. They form an "eye-shape" with the contact area (Fig. 4(a)). This semi-elliptical shape is directly linked to the friction coefficient through the $\sigma 2$ isostatic at the surface and the fretting direction of the ball (Lawn, 1967). The occurrence of two symmetrically oriented cracks is caused by the alternative movement of the spherical pad.

Cross-section $z=0$ (Fig. $4(b)$ ) shows that these two principal fretting fatigue cracks have two main inclinations in $(x 0 y)$ plane (Fig. 5). The angle of initiation is different from the angle of propagation. The angle of initiation (Stage I, Forsyth, 1963 ) follows cristallographical and more precisely preferential sliding planes. Crack propagation is influenced by both the static traction and fretting contact. At a depth of approximately 20 $\mu \mathrm{m}-30 \mu \mathrm{m}$ each crack branches at an angle of approximately $55-65$ deg from the surface and then extends in this same direction throughout the experiment. The two external loadings influence the propagation from this depth until the end of the test. These cracks were studied in microscopic detail and no detectable plastic zone at the tip of the cracks was observed.

A crack network exists in the antagonist spherical specimen. This counterface is only submitted to fretting loading (fretting wear). The two longest cracks of this piece are located opposite

Table 3 The contact data

Fn: $1000 \mathrm{~N} \Rightarrow 900 \mathrm{~N}$ after 100 runs.

Q: $\pm 930 \mathrm{~N}$.

2a: $3.6-3.7 \mathrm{~mm}$

2c: $2.2-2.3 \mathrm{~mm}$

f: 1.2 

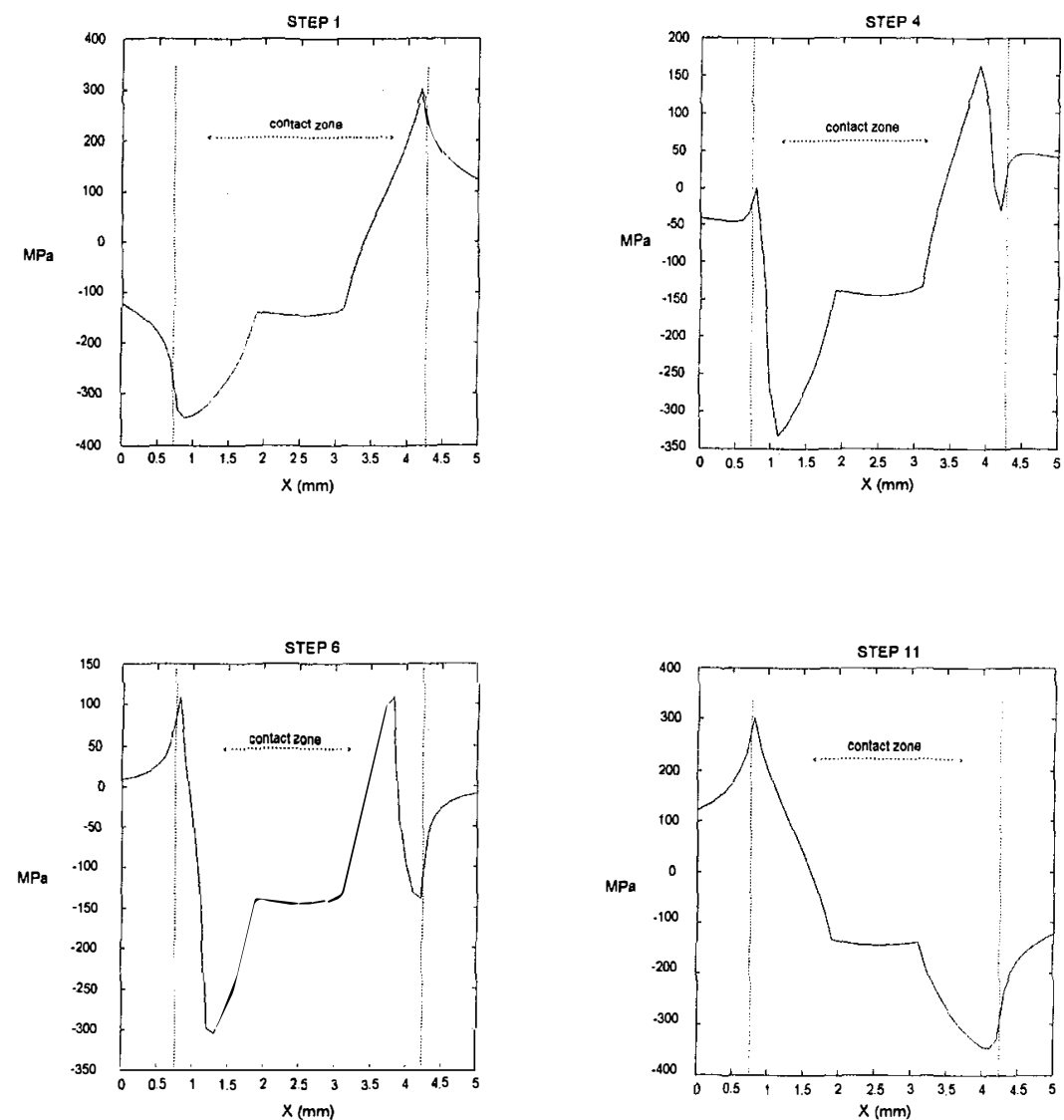

Fig. 6 Variation of $\sigma \times x$ stress field at the surface of the slab for 4 steps of the 11 step-cycle for a 7075 alloy. (See experimental conditions Table 2.)

to the two principal cracks of the plane specimen. These fretting wear cracks are shorter than the fretting fatigue cracks, but propagate in the same direction. It may be concluded that the first orientation of the fretting fatigue cracks is governed by the fretting conditions. Obviously, the fretting fatigue cracks propagate faster than the fretting wear cracks, as the SIF level is higher.

\section{Results and Discussion}

The operating fretting conditions are now estimated. Each loading cycle is incrementally described to take into account hysteresis generated by friction. The two main cracks are localized within the contact area. Their crack paths are predicted at different numbers of cycles.

IV.1 Main Crack Location. A simple explanation holds for the two main crack locations. The $\sigma x x$ contact stresses undergo their biggest gradient and also greatest values during a whole loading cycle (Fig. 6) at the interface of the sticking and the sliding zones. Note that in these fretting fatigue tests, the traction $\sigma_{D}$ generates tensile stresses $\sigma x x$ on its own which are added onto the contact stresses $\sigma x x$. The stick-slip boundary is alternatively submitted to a maximum $\sigma x x$ traction and a maximum $\sigma x x$ compression during a loading cycle. In the meantime, the sticking zone is subjected to a very small variation of $\sigma x x$. The $\sigma x x$ stress oscillates with each reversal of the shearing force. As pointed out by O'Connor (1981), initial yielding may occur at the surface for sufficiently large friction coefficients, as is the case for these experiments. The localised yielding could lead to the initiation of cracks by a process of extrusion and intrusion of the slip bands. This wide range of $\sigma x x$ fatigues the two domains concerned where cracks are more likely to initiate.
IV.2 Mixed Mode and Non-Proportional Conditions. The two cracks initiated within the contact area are modeled. These cracks are geometrically identical (length, orientations). A crack profile is approached either with one segment (straight crack) or with several segments (bent crack) (Fig. 5). The angle of crack extension is predicted for both cracks for three cases corresponding to three different numbers of cycles. Case one deals with straight inclined cracks of length $0.3 \mathrm{~mm}$. Cases two and three deal with bent cracks of, respectively, $1.35 \mathrm{~mm}$ and $1.66 \mathrm{~mm}$ length described with two segments. $K I$ and $K I I$ variations during a load cycle for the $1.35 \mathrm{~mm}$ long crack are reported in Fig. 7. Non-proportional mixed-mode I + II conditions act at the tip of each crack. $K I$ remains predominant compared to $K I I$.

The fretting fatigue crack model shows that either mode I or mode II is dominant, depending on the loading conditions. The two main cracks are, for instance, mainly subjected to $K I I$ under fretting loading while they undergo mixed-mode I + II under external traction, with dominant mode I. Note that the mode II is due to interactions between cracks.

IV.3 Prediction of Crack Path. As mentioned in Section II.2, under non-proportional loading, classical criteria predict an angle of crack growth different at each loading step. The prediction of crack growth direction is performed through a complementary factor leading to the determination of the loading step at which a crack propagates. The crack angle predicted by the classical criteria at this specific step is supposed to be the real crack path. If it correlates the experimental crack path angle, the new factor is effectively the governing parameter for the propagation under fretting fatigue loading. Consequently, the values of $K I$ and $K I I$ and the state of each crack at the propagation step are known. 


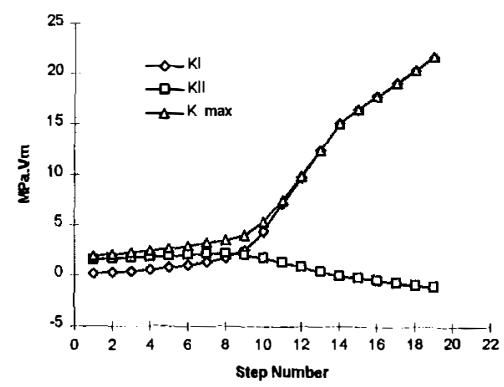

Fig. $7(a)$ Variation of $K I, K I I$ and $K \sigma$ max for crack 1, during a whole cycle

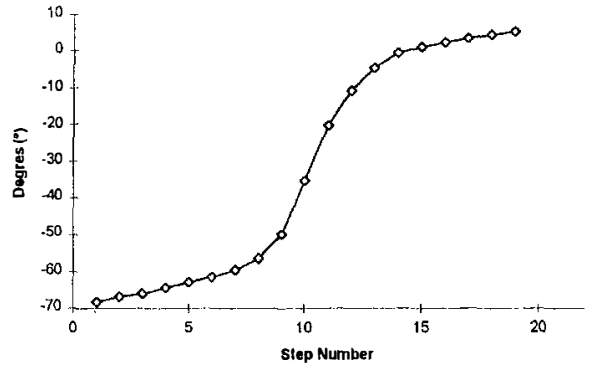

Fig. 7 (b) Theoretical predicted crack angles at each step of the cycle, for crack 1

Three complementary factors, already proposed (see section II.2) are considered here. They are the maximum value of $\overline{K I}, K_{\sigma}^{\max }$ (written $\left(K_{\sigma}^{\max }\right)_{\max }$ ) or $K_{\tau}^{\max }$ over a whole cycle. At each step of the fretting loading cycle, $K_{\sigma}^{\max }, K_{\tau}^{\max }$ which are $\theta$ related, determine the crack growth angle $\theta_{0} . \overline{K I}$ is directly calculated through $K I, K I I$, and $\theta_{0}$. Similar variations of $K_{\sigma}^{\max }, \overline{K I}$, and $K_{\tau}^{\max }$ are obtained over a whole fretting fatigue loading cycle corresponding to the experiments conducted here. They reached their maximum value at the same time, which is when $K I$ is maximum. Therefore, only the evolution of $K_{\sigma}^{\max }$ is reported in the following discussion. As a first approach, the propagation step is specified by $\left(K_{\sigma}^{\max }\right)_{\max }$.

Parallel to this first approach, an original complementary parameter is proposed here: the zero value of $K I I$. This step need not necessarily correspond to the maximum value of $K I$. It means that the crack tends to reach a pure mode I state to propagate under fretting fatigue conditions. According to Forsyth's theory (1963), after a stage I propagation process, a crack branches to remain open (Mode I) all along the stage II development. Under non-proportional loading, a crack cannot stay open during a whole load cycle, as $K I / K I I$ is not constant. Nevertheless, this second approach supposes that cracks propagate as stage II cracks, by a mode I process, even if they undergo mixed mode I + II loading during the rest of the load cycle.

Crack Angle Results. The predicted crack path directions are reported in Table 4 , resulting from the $\left(K_{\sigma}^{\max }\right)_{\max }$ approach and the $K I I=0$ approach, respectively labeled No. 1 and No. 2 in table 4 . The angles are calculated with reference to the initial crack direction and for three different crack lengths. The $0.3 \mathrm{~mm}$ long crack is straight. The two other cracks are kinked.

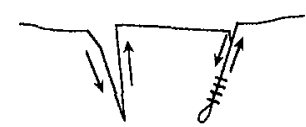

Crack 1 propagates

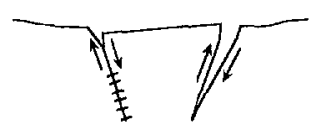

Crack 2 propagates $\uparrow \downarrow$ forward slip zone,$\downarrow \uparrow$ backward slip zone,$\neq$ closed zone,$>$ open zone

Fig. 8 State of each crack at the step of propagation determined when $K \sigma$ max is maximum

As was said before, during its evolution the crack branches once and then keeps growing in the same direction. So, before and after branching each crack grows in a self similar manner. The experimental crack path direction thus equals zero.

Each of these two approaches proposes a propagation process under fretting fatigue conditions. $K I$ and $K I I$ values and the state of each crack at its propagation step are different according to these two methods. The only way to ensure the validity of these methods is to compare the theoretical conclusions on the propagation process with the experimental evidence suggested by the test data.

The two different behaviors of the cracks described by these methods are analyzed in the next section. The results obtained by the $\left(K_{\sigma}^{\max }\right)_{\max }$ approach are presented first. It is shown that this approach, already proposed under non-proportional conditions, cannot describe the propagation process induced by these fretting-fatigue conditions with certainty. The $K I I=0$ approach is then tested. This approach correlates the experimental results and also proposes logical conclusions.

1) $\left(K_{\sigma}^{\max }\right)_{\max }$ Approach. In this case, the theoretical crack paths are more or less in agreement with the experimental observations (see Table 4 and Section IV.3 "Crack Angles Results") . For each crack, $K_{\sigma}^{\max }$ is maximum when $K I$ also reaches its maximum value. Thus, the two cracks propagate at two different and opposite times. $K I$ is maximum for crack 1 at the first step of the cycle, when the tangential force equals $\left(+Q^{*}\right)$. It is maximum for crack 2 at the last step, the tangential force equals $\left(-Q^{*}\right)$.

State of the Crack at Each Propagation Step. The stickslip-open configuration along the cracks are reported in Fig. 8.

The propagating crack is open whilst the second one is partially closed. The fretting loading and the static traction have their own effect on the state of each crack. The normal forces acting on the surface push down the section of the contact between the two cracks (plug effect, see Fig. $9(b)$ ). Thus, the imbalance of these forces creates interfacial slip. The tangential force, maximum at this step, stretches the open crack and traps the crack situated at the opposite side of the contact. Sliding along crack 2 eases crack 1 opening and vice versa. This stretchtilt mechanism (Dubourg et al., 1992) arises from the fretting loading. At the same time, the static traction accentuates the relative displacements along the cracks.

Discussion. This first approach leads to non-satisfactory conclusions. The theoretical predicted crack angles do not show a significant correlation with the experimental observations ( Ta-

Table 4 Prediction of crack path direction on 7075, for three crack lengths

\begin{tabular}{|c|c|c|c|c|c|c|}
\hline \multirow[b]{3}{*}{ Crack. No. } & \multicolumn{6}{|c|}{ Crack length } \\
\hline & \multicolumn{2}{|c|}{$0.3 \mathrm{~mm}$} & \multicolumn{2}{|c|}{$1.35 \mathrm{~mm}$} & \multicolumn{2}{|c|}{$1.66 \mathrm{~mm}$} \\
\hline & 1 & 2 & 1 & 2 & 1 & 2 \\
\hline $\begin{array}{l}\text { No. } 1 \theta 0\left(^{\circ}\right) \\
\text { No. } 2 \theta 0\left(^{\circ}\right)\end{array}$ & $\begin{array}{r}14.02 \\
8.77\end{array}$ & $\begin{array}{r}-15.31 \\
-0.48\end{array}$ & $\begin{array}{r}5.62 \\
-0.38\end{array}$ & $\begin{array}{l}-1.61 \\
-0.47\end{array}$ & $\begin{array}{l}6.3 \\
0.5\end{array}$ & $\begin{array}{l}-7.7 \\
-0.2\end{array}$ \\
\hline
\end{tabular}




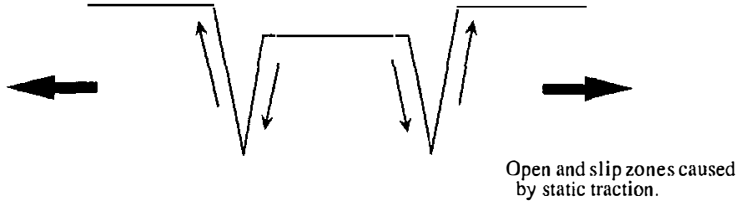

Fig. 9(a)

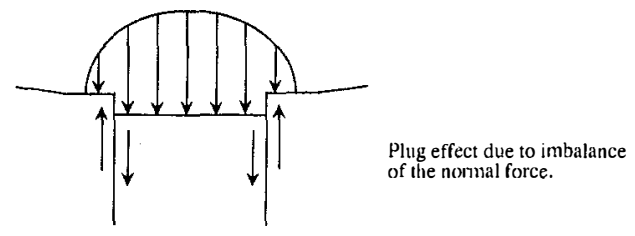

Fig. $\mathbf{9}(b)$

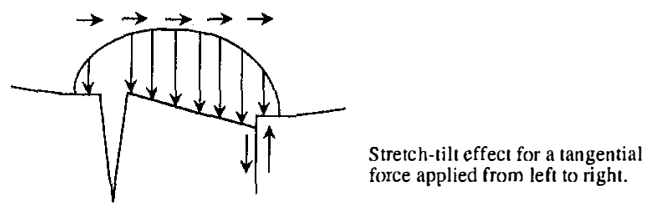

Fig. 9(c)

Fig. 9 Mechanisms induced by external loadings;(a) Slip zones induced by static traction; (b) Plug effect caused by normal forces; (c) Stretchtilt effect caused by tangential force.

ble 4). Each crack propagates when $K_{\sigma}^{\max }$ is maximum, and equivalently when $K I$ is maximum. Hence, the determination of the moment of propagation is only achieved using $K I$ whatever the value of $K I I$, whereas the corresponding angle of crack extension is calculated through $K I$ and $K I I$. Here, new experiments are necessary to highlight this point.

2) $(K I I=0)$ Approach. This second assumption leads to theoretical angles of crack extension in very good agreement with the experimental observations (Table 4 ). The propagation step is no longer linked to a characteristic stage of the loading cycle, i.e., maximum absolute value of $Q$, for instance, and it is no longer a symmetrical and systematic phenomenon. As was shown previously, the frettingloading alone rather involves $K I I$, and mixed-mode I + II conditions result from the uniaxial traction alone. Therefore, the zero-value of $K I I$ is reached through a combination of those two loadings. The coupling effect of the two external loadings on propagation is also experimentally observed.

State of Crack at Each Propagating Step. Sliding along a crack is the superposition of: forward slip for crack 1 and backward slip for crack 2 under static traction (Fig. $9(a)$ ). backward slip for crack 1 and 2 under fretting loading (Fig. 9(c)) with a tangential force applied from left to right (stretch-tilt effect). If this force is from right to left, the forward slip occurs along the faces of both cracks.

The $(K I I=0)$ step is reached when the slip displacements caused by the two loadings are equal in absolute value and opposite in sign. The states of the cracks are presented for the two steps corresponding to crack 1 propagation and crack 2 propagation (Fig. 10).

Crack 1 propagation. The propagating crack is completely open but its opening displacement is not maximum since the absolute value of the tangential force is not maximum. Crack 2 is partially open: an open zone, a backward slip zone and another open zone divide it from mouth to tip. It was initially completely open at the maximum value of $Q\left(-Q^{*}\right)$.
Crack 2 propagation. Similar phenomena occur at crack 2 propagation step. There is no open zone at crack 1 tip when crack 2 propagates as $K I I(2)=0$ does not correspond to the same absolute value of $Q$.

Discussion. These theoretical results correlate very well with the experimental results. Under the $K I I=0$ hypothesis, $K I$ and $K I I$ both play a role in the process of propagation. $K I I$ by equalling zero establishes the right propagation step. Then the mixed-mode crack propagates under pure mode I. This is consistent with an energy approach. Mode I appears as an equilibrium stage for propagation, but the two external loadings participate in the propagation process as observed experimentally.

As the crack propagation was not directly observable during the experiments, it was not possible to guess the real mode of propagation. A direct visualization of crack propagation during experiments was not possible. Therefore, no information was obtained on the crack propagation process. Nevertheless, the experimental observations give the crack angle. The model together with the proposed approach allows us to determine:

1 The crack propagation moment.

2 The real crack angle.

3 The crack propagation process.

The step of propagation is determined and this will enable further study for the prediction of crack growth rate under fretting fatigue loading. The determination of the crack path under non-proportional loading is performed with a two step method. First, classical criteria are applied to determine crack path direction at each loading step. Second, the zero-value of KII specifies the propagation step and thus enables the selection of the real crack path over the whole loading cycle.

\section{Conclusion}

In this paper, a combination of both experimental and theoretical studies is used to lead to a better understanding of the crack propagation processes under non-proportional conditions. The prediction of the direction of crack extension under fretting fatigue loading is performed. The main problem raised under these loading conditions is the presence of non-proportional loading at the tip of the cracks.

This study is divided into two main parts. The formulation of a theoretical tool to model fatigue crack problems under mixed mode conditions constitutes the first part of this work. Second, the application of this model to explain crack behavior encountered during fretting fatigue experiments is presented.

A theoretical model based on the dislocation theory solves the contact problem so as to determine $K I$ and $K I I$ and the corresponding distribution of the stick, open and slip zones, along the faces of each crack. The description of the fretting contact is performed using a unilateral contact analysis with friction. Three classical criteria are implemented into the model to predict the angle of crack growth under mixed mode conditions. The experimental angles of propagation under fretting fatigue loading cannot be directly predicted by these classical criteria.

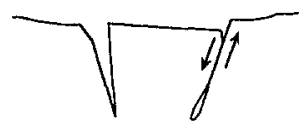

Crack 1 propagates

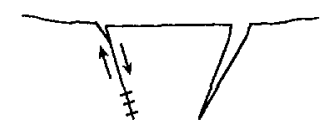

Crack 2 propagates $\uparrow \downarrow$ forward slip zone,$\downarrow \uparrow$ backward slip zone,$\neq$ closed zone , > open zone

Fig. 10 State of each crack at the step of propagation determined when $K I=0$ 
Experimental fretting fatigue tests are first carried out and cracks form during the test. The running fretting conditions are estimated from experimental observations and recorded data. The stress intensity factors at the tip of the cracks are calculated with the fretting fatigue crack model under these loading conditions.

A new methodology based on a complementary factor is proposed to predict crack growth direction. First, classical criteria are applied to determine crack path direction at each loading step. Secondly, the zero-value of $K I I$ specifies the propagation step and thus selects the real crack path over the whole loading cycle. The $K I I=0$ method gives predicted crack angles in very good agreement with the experimental results. Under this assumption, the crack extends in a pure mode I, even if it undergoes mixed mode conditions throughout the loading cycle. Under this multiaxial loading, Mode I appears as an equilibrium stage for crack propagation. This propagation mode also has a logical meaning, considering an energy approach. Consequently, it is shown that the cracks subjected to fretting fatigue loading extend when they are only subjected to pure mode I. It is also proved that the fretting loading and the static bulk traction both act on the propagation process. This model also permits the determination of the propagation step over a whole loading cycle. The values of $K I$ and $K I I$ at this specific step are determined. This is an important step for the determination of fatigue crack growth rate and more specifically of fatigue crack growth laws under fretting fatigue loading.

The experimental observations do not permit the estimation of the propagation mode. Only the combination of the theoretical model with the experimental evidence enables understanding of the propagation process under fretting fatigue loading. The capability of the present model to consider non-proportional problems is thus demonstrated.

The need for new experiments involving non-proportional conditions remains a priority. New tests should be performed in order to try to generalize these initial conclusions on the fretting fatigue experiments.

This study in determining the real stage of propagation during a loading cycle is a first step in resolving crack propagation under complex loading.

\section{Acknowledgments}

This work was supported by STPA France. The authors would particularly like to thank Mr. Gauthier (STPA) who enables this study to be performed and wish to remember Professor Godet (LMC, INSA Lyon) who shared so much of his time on fretting studies. Thanks are also due to P. Reybet-Degat for implementing and carrying out the experiments at the Ecole Centrale of Lyon and also for examining the experimental data.

\section{References}

Berthier, Y., Colombié, C., Lofficial, G., Vincent, L., and Godet, M., 1986, "First and Third Body Effects in Fretting. A Source and Sink Problems," 12th Leeds-Lyon Symposium: Global studies of mechanisms and local analysis of surface distress phenomena, D. Dowson, C. M. Taylor, M. Godet, D. Berthe, eds., pp. $81-90$.

Bold, P. E., Brown, M. W., and Allen, R. J., 1992, “A Review of Fatigue Crack Growth in Steels Under Mixed Mode I and II Loading," Fatigue Fract. Engng. Mater. Struct., Vol. 15, No. 10, pp. 965-977.

Bower, A. F., 1988, “The Influence of Crack Face Friction and Trapped Fluid on Surface Initiated Rolling Contact Fatigue Cracks," ASME Journal of Tribology, Vol. 110, pp. 704-711.

Brown, M. W., and Miller, K. J., 1973, “A Theory for Fatigue Failure Under Multiaxial Stress-Strain Conditions," Proc. Inst. Mech. Engrs., Vol. 187, pp. $745-755$.

Comninou, M., 1977, “The Interface Crack in a Shear Field,” ASME Journal of Applied Mechanics, Vol. 45, pp. 287-290.

Dubourg, M. C., Mouwakeh, M., and Villechaise, B., 1988, “Interaction Fissure-Contact_-Etude Theorique et Expérimentale," J. of Theoretical and Applied Mechanics, Vol. 7, No. 5, pp. 623-643.

Dubourg, M. C., and Villechaise, B., 1989, "Unilateral Contact Analysis of a Crack with Friction," European J. Mech., A/Solids, Vol. 8, No. 4, pp. 309-319.
Dubourg, M. C., 1989, “Le Contact Unilatéral avec Frottement le Long de Fissures de Fatigue dans les Liaisons Mécaniques," Thèse: Doctorat, Institut National des Sciences Appliquées de Lyon, 253 p.

Dubourg, M. C., and Villechaise, B., 1992a, "Analysis of Multiple Fatigue Cracks-Part I: Theory," ASME, JOURNAL OF TRIBOLOGY, Vol. 114, pp. 455461.

Dubourg, M. C., Godet, M., and Villechaise, B., 1992b, “Analysis of Multiple Fatigue Cracks-Part II: Results," ASME Journal OF TriBology, Vol. 114, pp. $462-468$

Dubourg, M. C., and Villechaise, B., 1992c, "'Stress Intensity Factors in a Bent Crack: A Model," Eur. J. Mech., A/Solids, Vol. 11, No. 2, pp. 169-179.

Dubourg, M. C., and Lamaca, V., 1994, "A Theoretical Model for the Prediction of Crack Field Evolution," Fretting Fatigue, ESIS 18, R. B. Waterhouse and T. C. Lindley, eds., Mechanical Engineering Publications, London, pp. 135147.

Dundurs, J., and Mura, T., 1964, "Interaction Between an Edge Dislocation and a Circular Inclusion," J. Mech. Phys. Solids., Vol. 12, pp. 177-189.

Erdogan, F., and Sih, G. C., 1963, "On the Crack Extension in Plates Under Plane Loading and Transverse Shear," ASME Journal of Basic Engineering, Vol. 85, pp. 519-525.

Fatemi, A., and Socie, D. F., 1988, “A Critical Plane Approach to Multiaxial Fatigue Damage Including Out-of-Phase Loading," Fatigue Fract. Engng. Mater. Struct., Vol. 11, No. 3, pp. 149-165.

Forsyth, P. J. E., 1963, "Fatigue Damage and Crack Growth in Aluminium Alloys," Acta Mettalurgica, II, 703.

Forsyth, P. J. E., 1981, 'Occurrence of Fretting Fatigue Failures in Practice,' in R. B. Waterhouse, ed., Fretting Fatigue, Elsevier Applied Science, London, pp. $99-125$.

Godet, M., 1984, "The Third Body Approach. A Mechanical View of Wear," Wear, Vol. 100, pp. 437-452.

Godet, M., 1988, "Modeling of Friction and Wear Phenomena," F. F. Ling and C. H. T. Pan eds., Approaches to modeling of friction and wear, SpringerVerlag, pp. 12-36.

Hills, D. A., and Comninou, M., 1985, “An Analysis of Fretting-Fatigue Cracks During Loading Phase," Int. J. of Solids Structures., Vol. 21, No. 7, pp. 721730.

Hoeppner, D. W., 1974, "Fretting of Aircraft Control Surfaces," AGARD Conf. Proc., No. 16i, AGARD, Munich.

Hourlier, F., d'Hondt, H., Truchon, M., and Pineau, A., 1982, "Fatigue Crack Path Behaviour Under Polymodal Fatigue," Rapport IRSID R E 958.

Hua, C. T., and Socie, D. F., 1984, "Fatigue Damage in 1045 Steel Under Constant Amplitude Biaxial Loading,' Fatigue Engng. Mater. Struct., Vol. 2, pp. $165-179$.

Johnson, K. L., 1985, Contact Mechanics, Cambridge University Press, 451 pp.

Kalker, J. J., 1990, Three Dimensionnal Elastic Bodies in Rolling Contact, Kluwer Academic Publishers, $314 \mathrm{pp}$.

Kanazawa, K., Miller, K. J., and Brown, M. W., 1977, "Low-Cycle Fatigue Under Out-of-Phase Loading Conditions,'” J. Engng. Mater. Tech., Vol. 99, pp. 222-228.

Kaneta, M., Yatsuzuka, H., and Murakami, Y., 1985, "Mechanism of Crack Growth in Lubricated Rolling/Sliding Contact," ASLE Transaction, Vol. 28, No. 3, pp. 407-414.

Keer, L. M., Bryant, M. D., and Haritos, G. K., 1980, "Subsurface Cracking and Delamination, in Solid. Contact and Lubrication," Ed. by H. S. Cheng and L. M. Keer, eds., ASME AMD, Vol. 39, pp. 78-85.

Keer, L. M., Bryant, M. D., and Hiratos, G. K., 1982, "Subsurface and Surface Cracking Due to Hertzian Contact," ASME, Journal of Lubricatron TECHNOLOGY, Vol. 104, pp. 347-351.

Keer, L. M., and Bryant, M. D., 1983, “A Pitting Model for Rolling Contact Fatigue," ASME Journal of Lubrication TechNology, Vol. 105, pp. 198 205.

Lawn, B. R., 1967, "Partial Cone Crack Formation in Brittle Material with a Sliding Spherical Indenter,' Proc. R. Soc., A299, pp. 307-317.

O’Connor, J. J., 1981, "The Role of Elastic Stress Analysis in the Interpretation of Fretting Fatigue Failures,'” R. B. Waterhouse, ed., Fretting Fatigue, Elsevier Applied Science, London, pp. 23-66.

Paris, P. C., 1964, "The Propagation of Cracks and Energy of Elastic Deformation," ASME Journal of Applied Mechanics, Vol. 80, pp. 1225-1230.

Pellerin, V., 1990, "Etude du Comportement en Usure Induite Sous Petits Débattements d'Alliages d'Aluminium et de Titane,"' Thesis, Ecole Centrale de Lyon, Lyon.

Reybet-Degat, P., and Vincent, L., 1994, “Cracking of Aluminium Alloys Under Fretting," NordTrib'94, Vol. 1, pp. 121-128.

Sheppard, S. D., Hills, D. A., and Barber, J. R., 1986, “An Analysis of Fretting Cracks. Part 2: Unloading and Reloading Phases," Int. J. of Solids Structures, Vol. 23, pp. 140-152.

Sheppard, S. D., Barber, J. R., and Comninou, M., 1987, "Subsurface Cracks Under Conditions of Slip, Stick and Separation Caused by a Moving Compressive Load," ASME J. Appl. Mech., Vol. 54, pp. 393-398.

Short, J. S., and Hoeppner, D. W., 1989, "The Maximal Dissipation Rate Criterion-I. Hypothesis and Theoretical Considerations," Engng. Fract. Mech., Vol. 33, No. 2, pp. 165-173.

Sih, G. C., 1974, “'Strain-Energy-Density Factor Applied to Mixed Mode Crack Problems,"' Int. J. Fract., Vol. 10, No. 3, pp. 305-321.

Sih, G. C., 1991, Mechanics of Fracture Initiation and Propagation, Kluwer Academic Publishers. 
Sin, H. C., and Suh, N. P., 1984, "Subsurface Crack Propagation Due to Surface Traction in Sliding Wear," ASME Journal of Applied Mechanics, Vol 51, pp. 317-323

Smith, E. W., and Pascoe, K. J., 1983, "The Behaviour of Fatigue Cracks Subject to Applied Biaxial Stress: A Review of Experimental Evidence,' Fatigue Engng. Mater. Struct., Vol. 6, No. 3, pp. 201-224.

Socie, D. F., 1987, "Multiaxial Fatigue Damage Models," J. Engng. Mater. Tech., Vol. 109, pp. 293-298.

Theocaris, P. S., and Andrianopoulos, N. P., 1982 "The Mises Elastic-Plastic Boundary as the Core Region in Fracture Criteria," Engng. Fract. Mech., Vol. 16, No. 3, pp. 425-432.

Tirosh, J., 1977, "Incipient Fracture Angle, Fracture Loci and Critical Stress for Mixed Mode Loading," Engng. Fract. Mech., Vol. 9, pp. 607-616.

Truchon, M., and Amestoy, M., 1981, "Etude Théorique et Expérimentale de

la Fissuration par Fatigue Sous Sollicitations Biaxiales," Rapport IRSID R E 872

Vincent, L., Berthier, Y., and Godet, M., 1987, "Fretting Wear and Fretting

Fatigue Damage,' Fatigue 87, Vol. 1, pp. 567-575.

Vincent, L., Berthier, Y., and Godet, M., 1992a, "Testing Method in FrettingFatigue: A Critical Appraisal," ASTM, Vol. 1159, pp. 33-48.
Vincent, L., Berthier, Y., Dubourg, M. C., and Godet, M., 1992b, "Mechanics and Materials in Fretting," Wear, Vol. 153, pp. 135-148.

Vincent, L., Godet, M., and Berthier, Y., 1994, Rapport final, Contrat "Programme Fretting-Fatigue," No. 9196030004717586, 178 pp.

Vingsbo, O., and Soderberg, D., 1988, “'On Fretting Maps,” Wear, Vol. 126, pp. $131-147$

Vingsbo, O., Odfalk, M., and Shen, N. E., 1989, "Fretting Maps and Fretting Behavior of Some FCC Metal Alloys," Wear Mater., pp. 275-282.

Waterhouse, R. B., 1972, Fretting Corrosion, Pergamon, Oxford.

Waterhouse, R. B., 1981, Fretting Fatigue, Elsevier Applied Science, London

Xiaogang, L., Qing, C., and Eryu, S., 1988, "Initiation and Propagation of Case Crushing Cracks in Rolling Contact Fatigue," Wear, Vol. 122, pp. 3343.

Zhou, R. Z., 1992, "Fissuration Induite en Petits Débattements: Application au cas d'Alliages d'Aluminium Aéronautiques," Thèse de Doctorat, Ecole Centrale de Lyon, pp. 161.

Zhou, Z. R., and Vincent, L., 1993, "Effect of External Loading on Maps of Aluminium Alloys,"' Wear, Vol. 162-164, pp. 619-623. 